\title{
GEOLOGIA E A REDISTRIBUIÇÃO SEDIMENTAR PÓS-CRETÁCICA DOS DEPÓSITOS DIAMANTÍFEROS DA REGIÃO AO SUL DE COROMANDEL (MG)
}

\author{
Kerley Wanderson Andrade ${ }^{1}$; Mario Luiz de Sá Carneiro Chaves ${ }^{2}$
}

RESUMO

\begin{abstract}
A região do Rio Douradinho ao sul de Coromandel apresenta períodos distintos em sua evolução tectônica. A fase mais antiga corresponde à sedimentação das tectonossequências meso e neoproterozóicas representadas pelos grupos Canastra, Ibiá e Araxá. Essas unidades compreendem a Faixa de Dobramentos Brasília, estruturada durante o Ciclo Brasiliano, estabelecendo seus contatos geológicos através de longas falhas de empurrão e zonas de cisalhamento, com baixo grau metamórfico associado. Durante o "Soerguimento do Alto Paranaíba", no intervalo Jurássico - Cretáceo, reativaram-se antigas estruturas regionais, e essas linhas de fraqueza da crosta condicionaram a colocação de intenso magmatismo de afinidade ultrabásica-alcalina, expresso também por intrusões de quimismo kimberlítico ou relacionadas, e ainda por extensos depósitos clásticos e piroclásticos (Grupo Mata da Corda). No Cenozóico, novos processos atuantes sobre as mesmas estruturas proporcionaram intenso retrabalhamento dos depósitos pretéritos originando sedimentos detríticos fanglomeráticos e aluviais, onde se concentrou a maior parte da mineralização diamantífera. É importante ainda ressaltar a relevância dos depósitos rudíticos fanglomeráticos, que constituem os principais alvos das atividades mineradoras e garimpeiras locais.
\end{abstract}

\begin{abstract}
The Douradinho River region, at south of Coromandel town, presents a tectonic evolution in different events. The older event is characterized by sedimentation of mesoproterozoic and neoproterozoic tectonosequences, related to Canastra, Ibiá and Araxá groups. These units compose the Brasília Fold Belt, which was structured during the orogenic Brasiliano Cycle, and show their geologic contacts as thrust faults and shear zones, with associated lower metamorphic grade. An uplift event in Jurassic-Cretaceous age evolved the "Alto Paranaíba Uplift", through the reactivation of older regional structures reactivation. Such weakness structures they had conditioned the emplacement of intense phase ultrabasic-alkaline of magmatic intrusions, as well as other intrusions of kimberlitic or related affinity and extensive clastic and piroclastic deposits (Mata da Corda Group). In Cenozoic age, new processes acting in same structures allowed the reworking of older deposits and caused the formation of detritic fanglomerate and alluvial deposits, where was concentrated the most part of diamond mineralization. It is also important to emphasize the relevance of these ruditic, fanglomerate deposits, that constitute the main focus of the mining and "garimpo" activities.
\end{abstract}

\section{INTRODUÇÃO}

A região de Coromandel é conhecida de longa data pela expressiva produção de grandes diamantes, muitos com mais de 100 quilates, representando a região brasileira onde a maior parte desses diamantes ditos "gigantes" foram descobertos. Embora sejam conhecidas inúmeras intrusões kimberlíticas e outras de natureza ultrabásica-alcalina nessa região, as rochas fontes primárias de tais diamantes ainda não foram descritas ou conclusivamente reconhecidas. A exploração diamantífera ocorre exclusiva e tradicionalmente em depósitos sedimentares, onde, os principais depósitos minerados, se associam a terrenos pós-cretácicos.

As megassequências proterozóicas constituem o substrato regional, e apresentam expressivo controle estrutural. Um largo período de manifestações magmáticas, de grandes proporções e afinidade ultrabásica-alcalina se desenvolveu no Cretáceo, favorecendo-se de tais estruturas pretéritas, e permitindo a deposição de extensos depósitos clásticos e piroclásticos, em associação a inúmeras intrusões de caráter kimberlítico (ou relacionado). A associação entre os eventos magmáticos e a sedimentação cretácica, bem como o posterior retrabalhamento desses depósitos durante o Cenozóico, constitui fator de particular importância no conhecimento da mineralização diamantífera.

O objetivo do presente estudo foi de, a partir do mapeamento geológico (Escala 1:50.000) de uma importante área diamantífera ao sul de Coromandel, estabelecer parâmetros de controle da mineralização através do estudo integrado do arcabouço précambriano, das intrusões kimberlíticas conhecidas, e de seus depósitos derivados cretácicos e cenozóicos.

\section{LOCALIZAÇÃO E CONTEXTO GEOLÓGICO REGIONAL}

A região de Coromandel situa-se no extremo oeste de Minas Gerais, nas proximidades da divisa com o Estado de Goiás (Figura 1). A área estudada abrangeu a bacia do Rio Douradinho, um afluente do alto Rio Paranaíba, na porção sul do município. Historicamente 
ela é conhecida pela descoberta de grandes diamantes, e tem produzido recorrentemente pedras de grandes dimensões, a exemplo do Presidente Dutra (408 ct 1949) e Douradinho III (82 ct - dec. 1940) (Barbosa, 1991). Em termos macrotectônicos, a região inserese no contexto da Província Tocantins em seu setor meridional (Almeida, 1977), representado pela Faixa de Dobramentos Brasília, a qual se estruturou durante o ciclo orogênico Brasiliano (630-490 Ma) (Seer, 1999; Seer \& Dardenne, 2000).
A tectonesseqüência inferior é representada pelo Grupo Canastra, formado principalmente por conjunto de quartzitos puros a ferruginosos, quartzosericita xistos e filitos (Campos Neto, 1984). Em contato tectônico definido por falhas de empurrão e zonas de cisalhamento (Seer, 1999) ocorre o Grupo Ibiá, que compreende uma alternância de metadiamictitos com clastos extremamente variados e filitos calcíferos esverdeados (calcifilitos). Em contato também de caráter tectônico, o Grupo Araxá sobrepõe

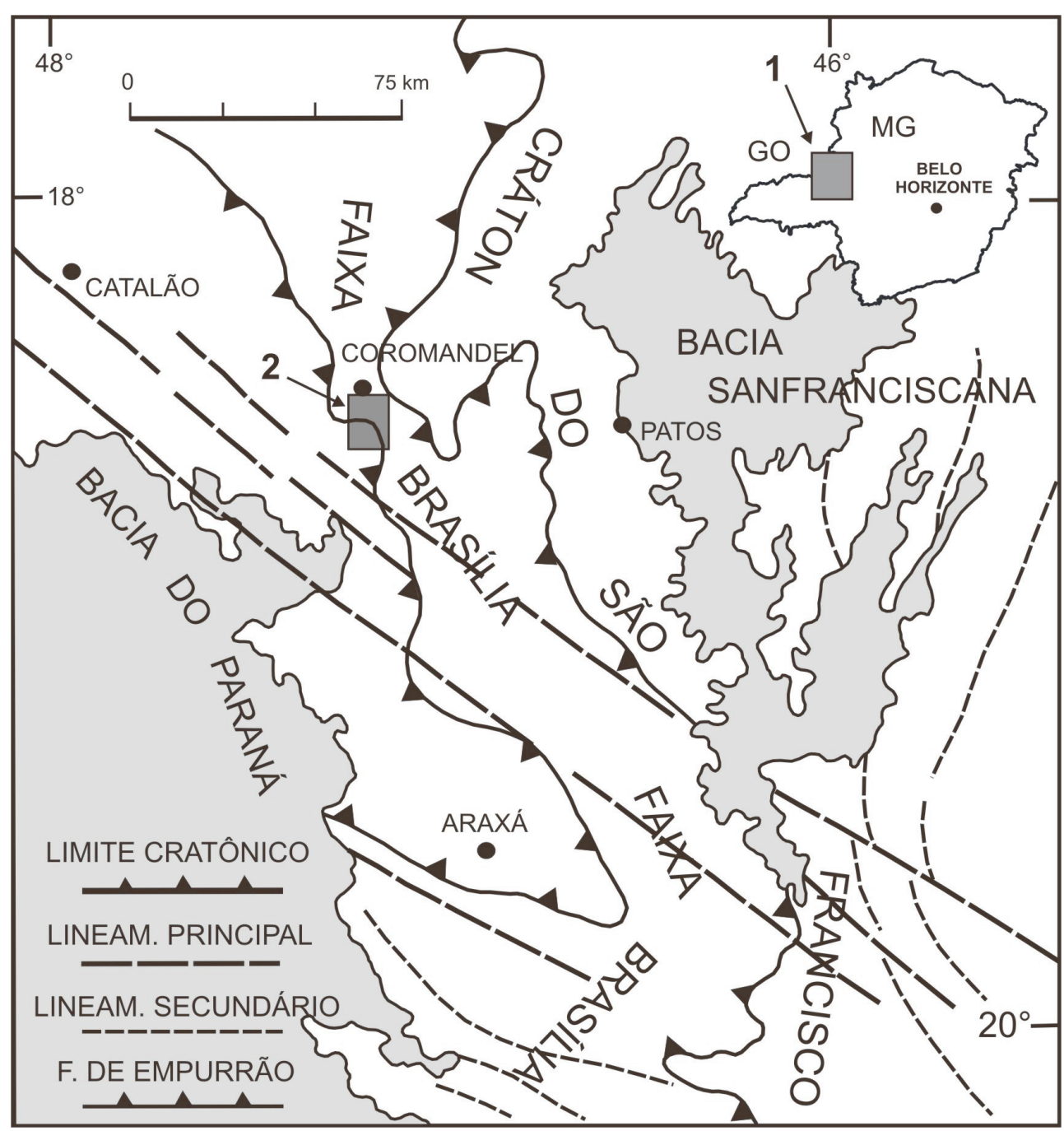

Figura 1: Localização da área estudada na porção oeste de Estado de Minas Gerais junto à fronteira com Goiás (em destaque -1), ressaltando seu posicionamento próximo à borda leste da Faixa de Dobramentos Brasília (em destaque - 2; base geológica segundo Heineck et al., 2003).

Como unidades representantes da Faixa Brasília ocorrem na região sequências metassedimentares proterozóicas que mostram deformação tangencial e aumento progressivo do gradiente metamórfico de leste para oeste, com vergência em direção ao Cráton do São Francisco (Fuck et al., 1994) verificando-se uma completa obliteração das relações estratigráficas entre suas unidades. Após o evento orogenético, tais unidades do cinturão orogênico se organizaram em um trend compressivo SW-NE constituindo sistemas de nappes e de empurrões imbricados (Simões \& Valeriano, 1990; Valeriano \& Simões, 1997; Seer, 1999). as demais unidades, constituindo associações de rochas metavulcânicas, metavulcanossedimentares e metassedimentares (Heibron et al., 1987) formadas por anfibolitos, micaxistos, quartzitos e xistos feldspáticos milonitizados (Seer, 1999; Seer et al., 2001).

No Cretáceo, desenvolveu-se expressivo evento sedimentar sobre grandes extensões dos terrenos pretéritos, durante a estruturação da Bacia Sanfranciscana. Tal evento caracterizou-se como o último ciclo geodinâmico sobre a área cratônica (Sgarbi et al., 2001), sendo representado por extensa associação sedimentar e vulcânica. Os derrames e depósitos 
clásticos e piroclásticos assim formados tiveram seu aporte na bacia gerada em regime tectônico de subsidência termal, em associação direta à estruturação do Soerguimento do Alto Paranaíba (Ladeira et al., 1971; Campos \& Dardenne, 1997a, b).

O Soerguimento do Alto Paranaíba consiste em um alto do embasamento que expõe as rochas proterozóicas, sendo facilmente identificado pelos grandes lineamentos que atravessam o continente desde a plataforma oceânica (Megalineamento $125^{\circ} \mathrm{AZ}$ ). A flexura gerada pela subsidência termal propiciou a deposição das unidades componentes da Bacia Sanfranciscana. O Grupo Santa Fé (Permo-Carbonífero), constitui a porção basal da bacia restringindo-se às suas paleodepressões, definido por uma sucessão de sedimentos glaciogênicos, com diamictitos associados a seqüências glácio-lacustres a flúvio-glaciais formadas de folhelhos, arenitos, conglomerados, ritmitos e grauvacas (Sgarbi et al., 2001; Campos \& Dardenne, 1997a).

O Grupo Areado (Cretáceo Inferior), estratigraficamente superior, corresponde a depósitos de ambiente desértico contendo sedimentos do tipo wadi, associados a conglomerados matriz-suportados e arenitos líticos de leques aluviais. Ocorrem também depósitos de playa lake e arenitos eólicos com estratificações cruzadas de grande porte, bem como depósitos flúvio-deltáicos, formados por arenitos de granulometria média até conglomerática (Sgarbi, 1989). O Grupo Mata da Corda (Cretáceo Superior), consiste em depósitos essencialmente vulcânicos e vulcanoclásticos; apresenta intrusões e derrames de kamafugitos, mafuritos, uganditos, além de kimberlitos. Associados a essas rochas, ocorrem depósitos vulcanoclásticos compostos de arenitos e conglomerados cineríticos (Barbosa et al., 1970; Sgarbi et al., 2000).

\section{GEOLOGIA DA REGIÃO DO RIO DOURADINHO}

Através de mapeamento geológico, efetuado na escala original de 1:50.000, estudou-se a região do Rio Douradinho ao sul de Coromandel, tendo em vista o conhecimento integrado do arcabouço pré-cambriano com as manifestações magmáticas (intrusivas, extrusivas e piroclásticas) do Cretáceo, bem como seus produtos sedimentares clásticos pós-cretácicos (Figura 2).

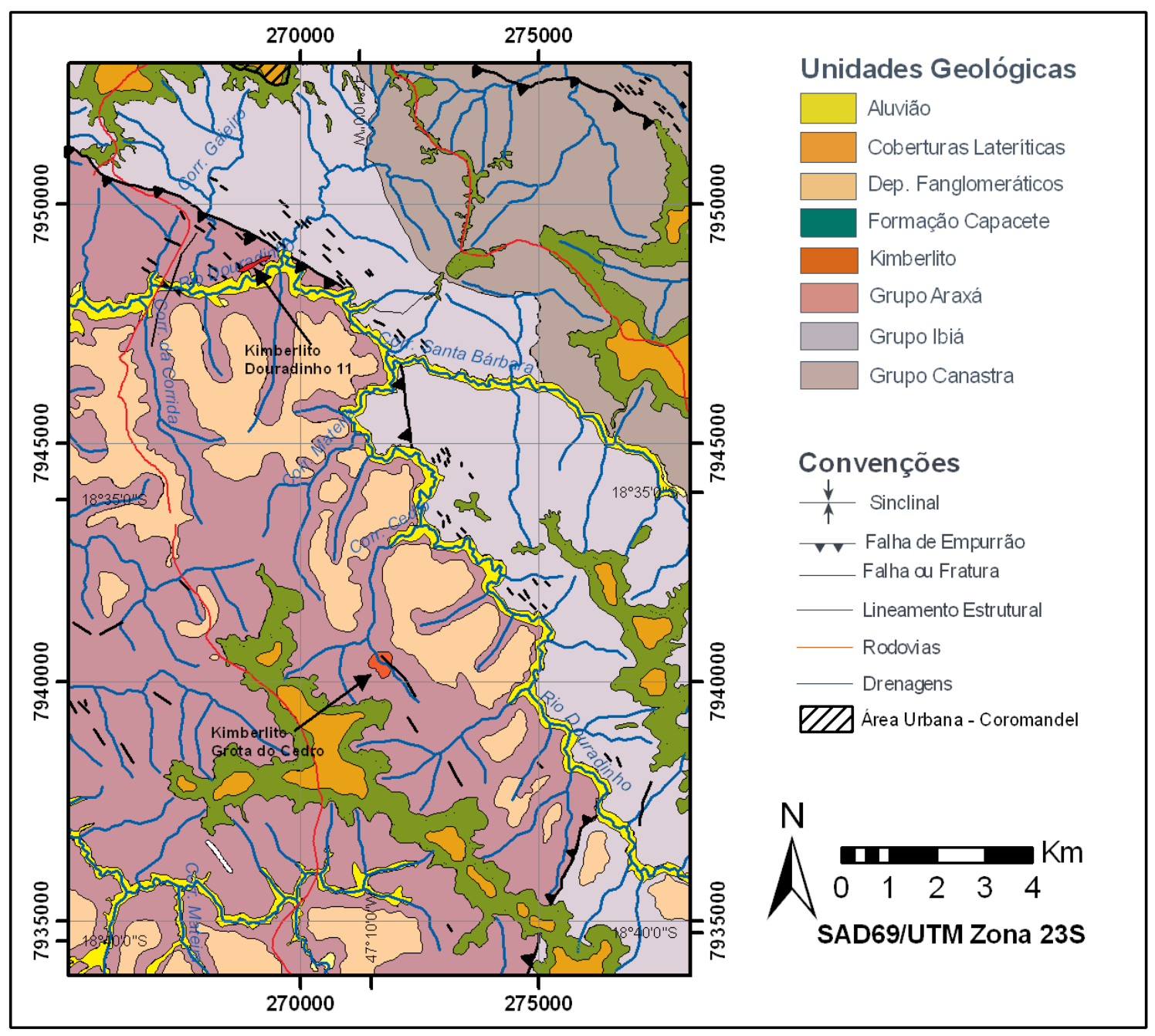

Figura 2: Geologia da região da bacia do Rio Douradinho ao sul de Coromandel (modificada de Andrade, 2008). 


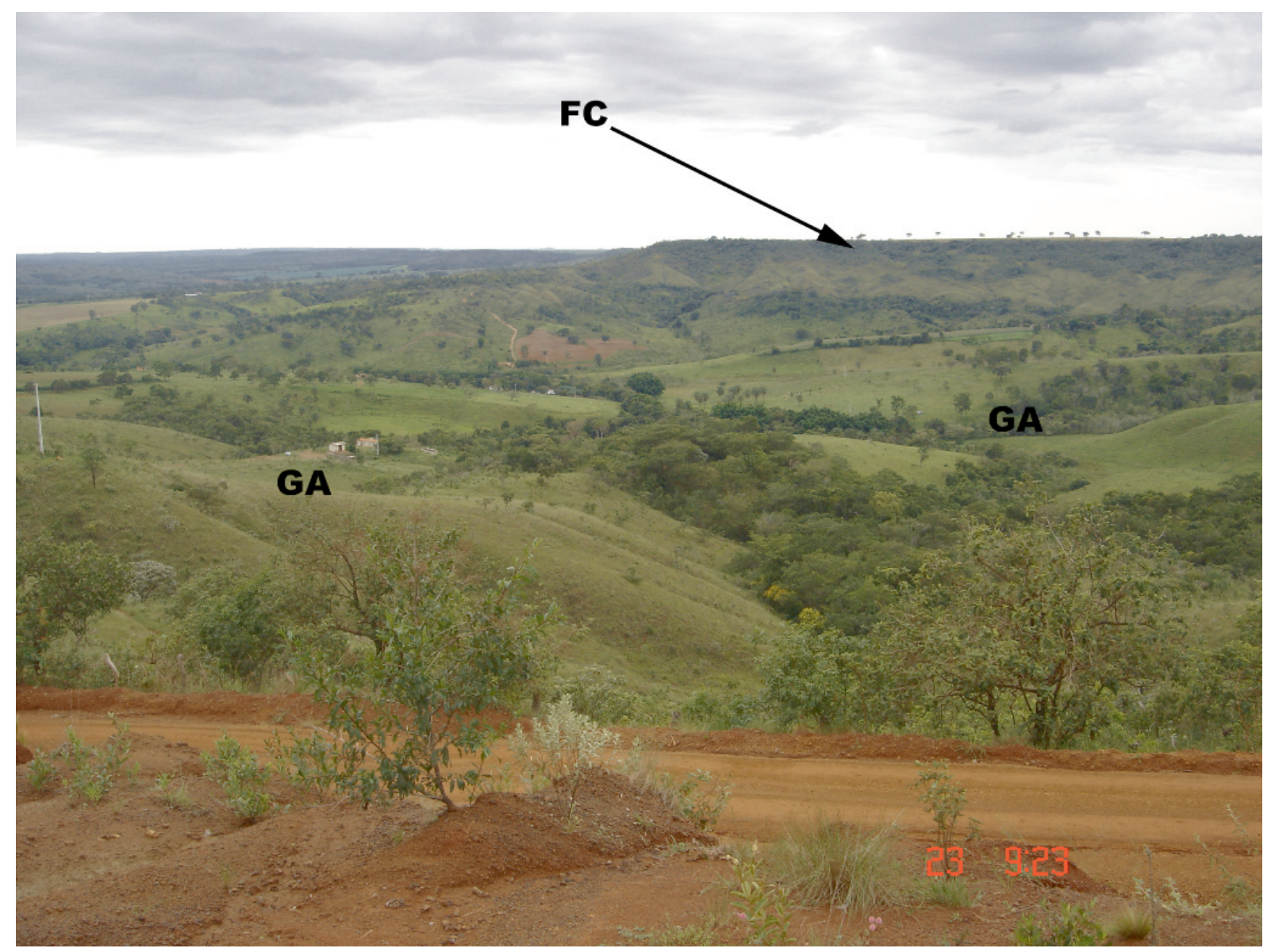

Foto 1: Aspecto arrasado do relevo ao sul da área de estudo, desenvolvido principalmente sobre os xistos do Grupo Araxá (GA), mostrando ao fundo as mesetas constituídas por rochas da Formação Capacete, do Grupo Mata da Corda (FC).

\section{ARCABOUÇO PRÉ-CAMBRIANO, SEDIMENTAÇÃO CRETÁCICA E DIAMANTES}

A maior parte da região é dominada por rochas do Grupo Araxá, aí constituído principalmente por quartzomicaxistos com intercalações métricas a decamétricas de quartzitos (Andrade, 2008). A unidade predomina nos baixios sobre faixa NW-SE atravessando toda a área, na margem sul da bacia do Rio Douradinho (Foto 1). Em contato tectônico, empurrado sobre tais rochas ocorre o Grupo Ibiá, na região formado exclusivamente por calcifilitos em geral bastante intemperizados. A nordeste da área, sotopondo rochas da unidade anterior, aparecem quartzitos com filitos subordinados, pertencentes ao Grupo Canastra. Tais unidades possuem ainda um relacionamento estratigráfico incerto, entretanto os mapeamentos regionais têm considerado um sequenciamento da base para o topo no sentido Canastra-Ibiá-Araxá (eg., Heineck et al., 2003).

Os litotipos cretácicos incluem arenitos e conglomerados com forte contribuição vulcânica, do Grupo Mata da Corda (Formação Capacete - Foto 2), além de intrusões kimberlíticas como as designadas "Grota do Cedro" e "Douradinho-11" (Andrade, 2008), de relacionamento temporal incerto com a unidade anterior. É mais provável que a Formação Capacete seja imediatamente posterior à fase principal das intrusões, tendo em vista a forte contribuição de minerais kimberlíticos na mesma. Na base, essa formação é formada por conglomerados e arenitos cineríticos, e no topo por uma sucessão de lavas e tufos vulcânicos com arenitos e siltitos associados. Diversos autores tem destacado uma provável associação dos diamantes de Coromandel com tais eventos magmáticos e/ou a seus produtos clásticos derivados (eg., Barbosa et al., 1970; Chaves, 1991; Read et al., 2004).

Devem ser ainda lembrados os trabalhos regionais de Tompkins \& Gonzaga (1989) e Gonzaga \& Tompkins (1991), os quais enfatizaram um possível relacionamento entre diamantes e os depósitos glaciogênicos do Neoproterozóico, representados na área pelo Grupo Ibiá. Os estudos mostraram, entretanto, que no Rio Douradinho tal unidade é constituída exclusivamente por calcifilitos, e que existem sedimentos aluvionares com diamantes mesmo acima da faixa de exposição da mesma (Figura 2). De tal maneira, para a aceitação desse modelo deve-se admitir que a unidade glacial do Grupo Ibiá tenha sido erodida (ou suprimida tectonicamente) e que a redistribuição dos diamantes ocorreu de modo exclusivo a partir dos depósitos cretácicos da Formação Capacete.

De fato, a ocorrência de diamantes nos conglomerados cretácicos da Formação Capacete também é localmente 
admitida, embora não constitua alvo importante de atividades exploratórias (Barbosa et al., 1970). A baixa demanda de exploração desses conglomerados deve-se principalmente ao fato de sua localização nas porções superiores dos platôs cretácicos, acima de $1.000 \mathrm{~m}$, onde inexiste abastecimento d'água suficiente de modo a favorecer o processamento do material mineralizado e sua cobertura laterítica (Andrade, 2008).

\section{DEPÓSITOS SEDIMENTARES PÓS- CRETÁCICOS}

Uma elaborada trama de sedimentação ocorrida durante o Cenozóico encontra-se amplamente distribuída pela região, correspondendo aos principais depósitos

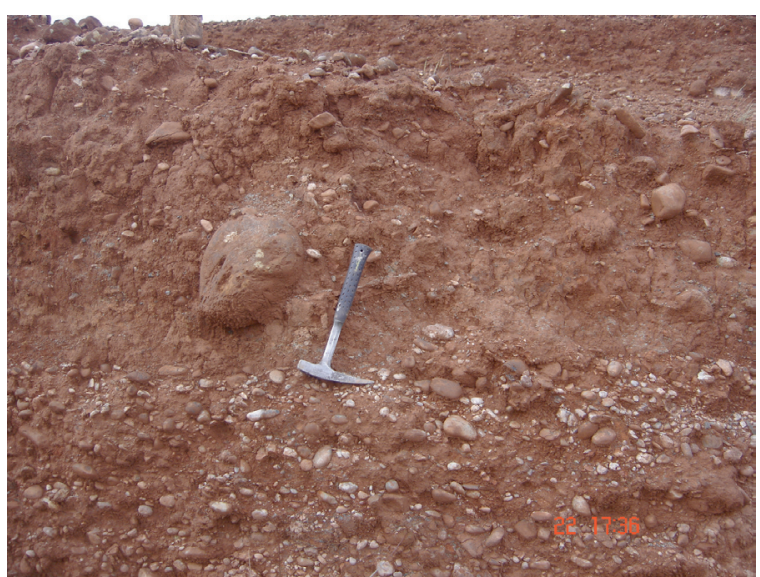

Foto 2: Aspecto geral do conglomerado cretácico da Formação Capacete (Grupo Mata da Corda), rico em blocos de quartzito (como o mostrado à esquerda do martelo), aflorando a nordeste da área nas proximidades da $M G-188$.

diamantíferos minerados há mais que um século em toda faixa do alto Rio Paranaíba, destacando-se, além do Rio Douradinho, os rios Dourado, Santo Inácio, Santo Antônio do Bonito e Santo Antônio das Minas Vermelhas.

Os depósitos cenozóicos são de dois tipos. Os mais antigos, possivelmente neogenos, correspondem a sedimentos detríticos fanglomeráticos. Esses depósitos apresentam forte controle estrutural, uma vez que ocorrem de modo preferencial ao sul do Rio Douradinho, no bloco de capa do falhamento de empurrão que define o contato entre os grupos Ibiá e Araxá. Eles se dispõem em camadas de espessura variando entre 2 e $15 \mathrm{~m}$, formadas na parte basal por corpos métricos lenticulares de cascalho, transversais (SW-NE) ao sentido das falhas de empurrão, localmente cobertas por areias imaturas de matriz areno-argilosa avermelhada contendo grânulos de quartzo, quartzito e xisto (Foto 3 ).

Tais depósitos sobrepõem os xistos do Grupo Araxá, possuindo matriz idêntica à das areias, e clastos variando de grânulo até matacão (Fotos 3 e 4), compostos de litologias de expressão local como xistos, quartzitos, silexitos, além de grãos detríticos de ilmenita e em menor quantidade de granada e diopsídio. A disposição

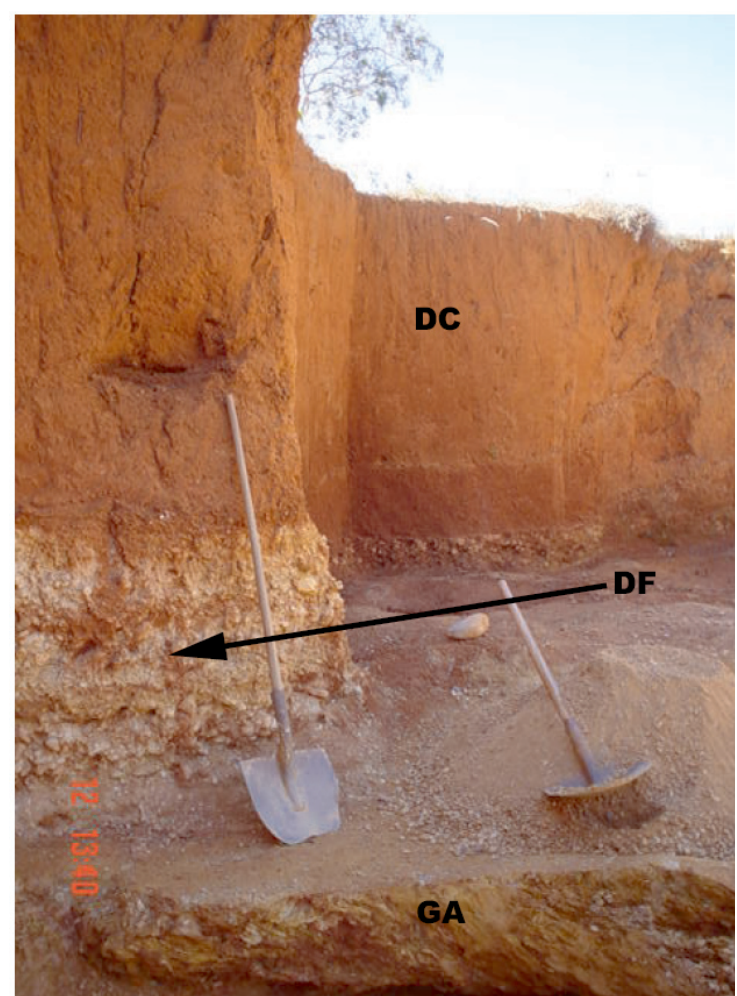

Foto 3: Camada basal métrica de cascalho diamantífero do tipo fanglomerático (DF), minerada às margens do Rio Douradinho, em sobreposição a xistos do Grupo Araxá (GA) e coberta por depósito coluvial arenoso (DC).

das barras arenosas quanto ao seu comprimento indica uma direção de transporte no sentido SW-NE nas ocorrências da parte central da área, e sentido N-S nos depósitos do centro-norte da mesma. Essas direções são sempre coincidentes com os platôs onde afloram conglomerados cretácicos, que apresentam clastos e matriz com características semelhantes.

Depósitos quaternários compreendem aluviões e terraços aluvionares que ocorrem ao longo das principais drenagens locais, como o Rio Douradinho e os córregos Santa Bárbara e da Cana. Dispostos como barras longitudinais ao sentido das drenagens, são compostos de sedimentos arenosos médios a grossos contendo grãos detríticos de quartzo, ilmenita, granada, diopsídio, micas e fragmentos líticos. Barras conglomeráticas aparecem nas porções internas das barras arenosas, contendo clastos que variam de seixo até matacão de quartzo, xisto, silexito e quartzito.

As drenagens mencionadas apresentam declividade suave, variando de $840 \mathrm{~m}$ a montante, no extremo SE da área, até próximo de $800 \mathrm{~m}$ a jusante, em seu limite centro-norte. As barras arenosas tem comprimento e espessura variáveis, em geral menores que $20 \mathrm{~m}$ x 2 $\mathrm{m}$, lobadas na direção das margens côncavas havendo deposição nas margens convexas, de fluxo mais lento (Foto 5). Intercalando-se às barras arenosas, os cordões de cascalhos possuem espessura e comprimento reduzidos em suas porções internas ocorrendo também em armadilhas encaixadas em zonas de falha nos micaxistos do Grupo Araxá. 


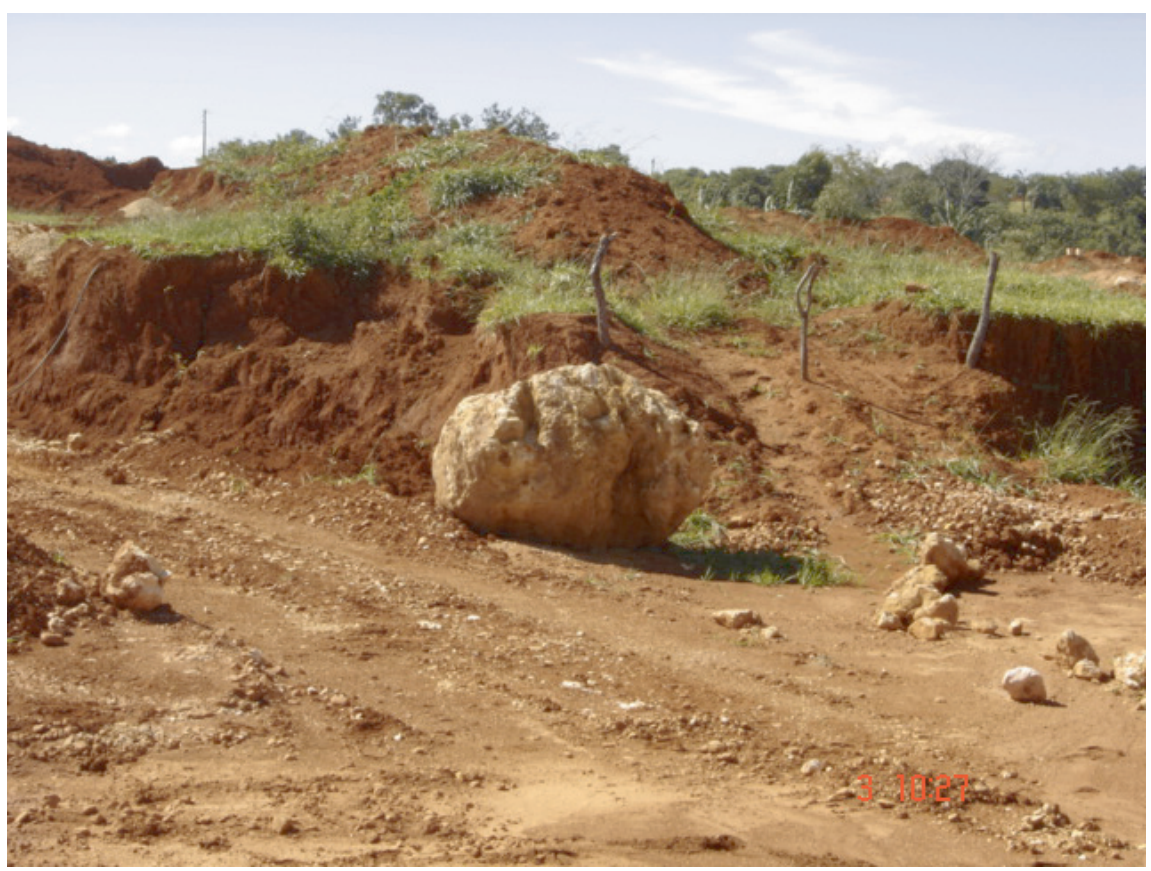

Foto 4: Depósito fanglomerático da margem esquerda do Rio Douradinho, contendo matacões isolados de silexito (cascalhos "emburrados" para os garimpeiros), o qual constitui o principal alvo da mineração na região.

\section{MODELO DE EVOLUÇÃO DOS DEPÓSITOS E REDISTRIBUIÇÃO DOS DIAMANTES}

A associação direta entre os depósitos diamantíferos fanglomeráticos e aluvionares com rochas kimberlíticas (ainda desconhecidas), como as que ocorrem nas imediações, é bastante plausível. Tal premissa, contudo, até então só pode ser aceita baseando-se em dados indiretos. Primeiramente, a existência de inúmeras intrusões kimberlíticas ou relacionadas na região é um forte argumento para que a fonte da mineralização possa ser proximal (Barbosa et al., 1970; Chaves, 1991). É ainda de especial relevância a tipologia desses diamantes, os quais exibem superfícies cristalinas deformadas (Foto 6) ou mesmo com alto grau de corrosão, feições geradas durante a intrusão da rocha fonte (Chaves et al., 2005, 2006). Outro aspecto é a ocorrência anormal de diamantes com alta quilatagem, que também apresentam essas características. Tal conjunto de fatores reforça a hipótese de uma fonte proximal, uma vez que em depósitos onde as fontes são distais, os diamantes tendem a possuir morfologia

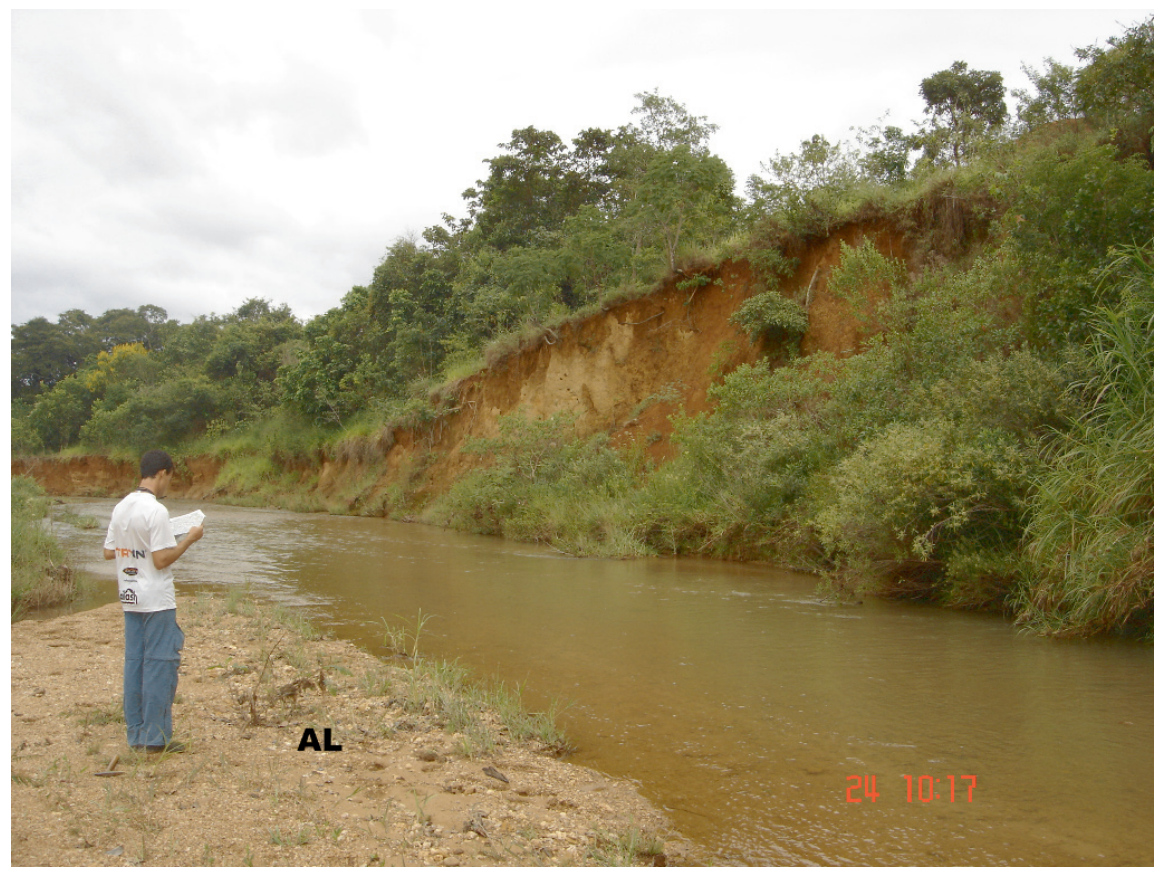

Foto 5: Aluvião recente do Rio Douradinho, mostrando a sedimentação ocorrida em sua margem convexa (AL). 


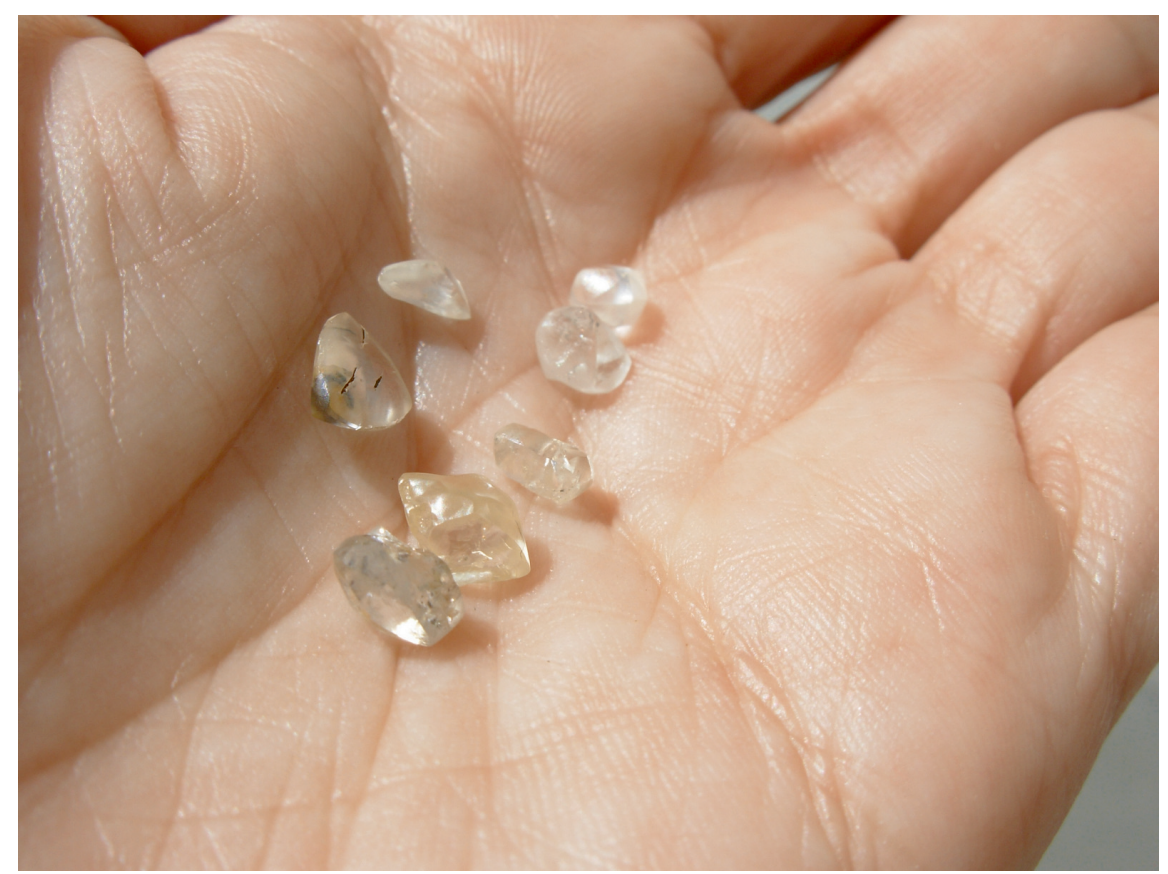

Foto 6: Diamantes recuperados no garimpo da Cooperativa dos Garimpeiros de Coromandel, no Rio Douradinho, mostrando seu principal aspecto superficial, as faces altamente dissolvidas.

cristalina regular (principalmente rombododecaedros), e em geral são de muito menor quilatagem (Chaves et al., 1998).

Em contexto regional amplo, a maior parte das intrusões kimberlíticas ocorreu no período entre 120 e $80 \mathrm{Ma}$. A idade mais antiga é referida ao Kimberlito Canastra-1, na Província Diamantífera da Serra da Canastra, a qual acusou $120 \mathrm{Ma}$ - Cretáceo Inferior (Pereira \& Fuck, 2005). Na região de Coromandel as idades indicaram emplacements no Cretáceo Superior, variando entre 95 Ma no Kimberlito Três Ranchos-4 (Read et al., 2004), 86-87 Ma no Kimberlito Poço Verde (Davis, 1977) e 83 Ma no Kimberlito Santa Rosa-4 (Skine, 1993; in Pereira, 2007), este último situado logo ao sul da área estudada.

Por outro lado, a redução gradativa da atividade ígnea já no Cretáceo Superior, associada com a reativação de antigos falhamentos proterozóicos, possibilitou o surgimento de altos estruturais em áreas constituídas de rochas mais rígidas do Grupo Canastra. Os quartzitos desta unidade, assim como as intrusões ultrabásicas e demais produtos vulcanoclásticos associados, representaram as prováveis fontes de suprimento dos conglomerados basais da Formação Capacete. Este fato é corroborado pela maior espessura dos conglomerados a leste, onde ocorrem tais quartzitos, e sua quase total ausência nas exposições observadas mais para oeste (Andrade, 2008). A matriz argilosa e a grande quantidade de magnetita, Mg-ilmenita e piropo presentes nessas rochas reforça uma forte contribuição kimberlítica e vulcanoclástica ao depósito, bem como possível aporte diamantífero (a exemplo da Mina de Romaria, a oeste da região, conforme Suguio et al., 1979). Sua configuração indica uma deposição em leques aluviais de alta energia devido à presença comum de blocos entre os clastos (Foto 2).
Os eventos tectônicos posteriores de acomodação desenvolvidos na região do Soerguimento do Alto Paranaíba, durante o Neogeno, foram também condicionados às estruturas pré-existentes, e permitiram o reajustamento dos blocos limitados pelas grandes falhas de empurrão. Essa nova estruturação promoveu o basculamento do bloco representado pelo Grupo Araxá, com um rebaixamento em direção a NW, próximo ao contato com o Grupo Ibiá (Figura 2). Por sua vez, tal rebaixamento favoreceu o aporte de sedimentos fanglomeráticos em direção ao Rio Douradinho, em drenagens de alta energia (Figura 3 ).

Existem diversas citações quanto à ocorrência de atividades neotectônicas na faixa circuncratônica sudoeste-sul-sudeste de Minas Gerais, bem como em áreas contíguas do Estado de São Paulo (eg., Campos \& Dardenne, 1997b; Etchebehere et al., 2007; Magalhães \& Trindade, 2005; Saadi, 1993). Em geral, os sedimentos resultantes de tais atividades são subestimados, já que não envolvem qualquer importância econômica. Os principais estudos que abrangeram a região de Coromandel, também não se ativeram aos depósitos fanglomeráticos, sendo em geral associados ao processo de sedimentação aluvionar recente (Barbosa et al., 1970). No entanto, depósitos de gênese similar e igualmente contendo mineralização diamantífera foram comprovados recentemente nas proximidades de Jequitaí, centro-norte de Minas Gerais (Chaves \& Bottino, 2000; Penha et al., 2005).

Nesse período, as porções mais elevadas do relevo correspondiam aos depósitos clásticos e vulcanoclásticos do Cretáceo Superior (Formação Capacete), onde se comprovou a atuação de processos neotectônicos (Foto 7). A tipologia e composição dos clastos e da matriz dos sedimentos fanglomeráticos é coincidente com a dos conglomerados cretácicos, assim como a presença 


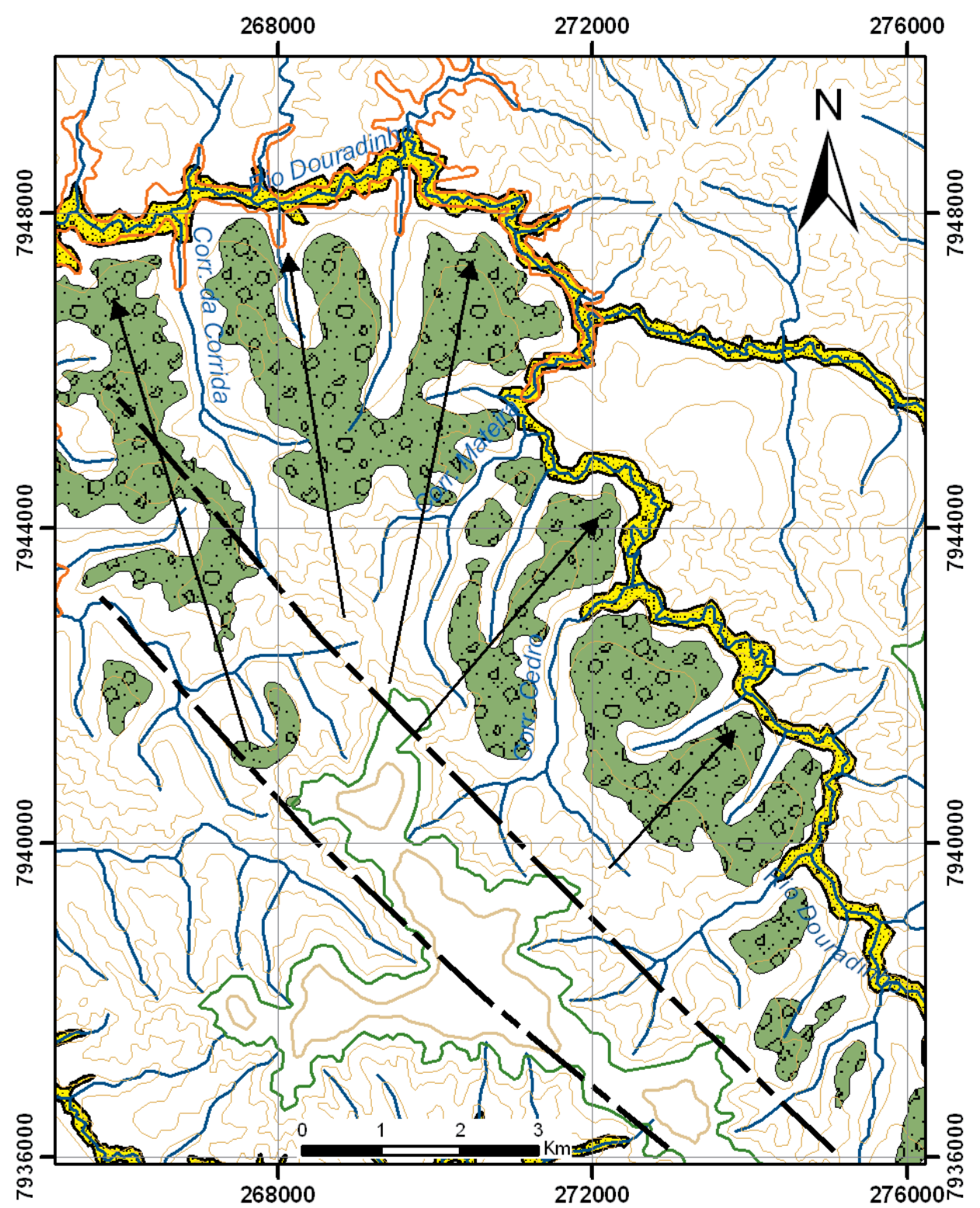

Legenda

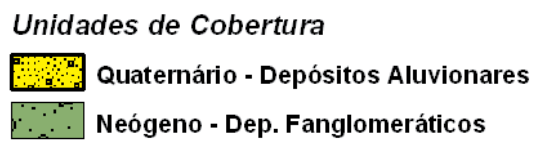

Altitudes

— $800 \mathrm{~m}$ - Menor Elevação

$1000 \mathrm{~m}$ - Maior Elevação

Estrutura

Lineamento Estrutural (125AZ)

Figura 3: Modelo para explicar o aporte de sedimentos (dado pelas setas pretas) cenozóicos da margem sul do Rio Douradinho, a partir dos terrenos soerguidos (>1.000 m) formados pelas coberturas cretácicas, tectonicamente controlados pelo lineamento estrutural $125^{\circ} \mathrm{AZ}$.

dos minerais associados, embora sua ocorrência nos primeiros esteja concentrada em uma fração granulométrica menor (Andrade, 2008). Tal redução na granulometria é mais evidente nos grãos de óxidos, que pelo retrabalhamento fluvial são encontrados em menor tamanho e quantidade. A presença de diamantes nesses depósitos é também indicativa do retrabalhamento de outros depósitos pretéritos.

A acomodação tectônica pós-cretácica (neogena?) favoreceu ainda o encaixe do curso do Rio Douradinho, em grande parte ao longo dos falhamentos condicionadores das unidades proterozóicas. Esse aspecto permitiu que seu leito se tornasse uma calha concentradora de sedimentos de toda região, tanto dos provenientes da erosão dos sedimentos fanglomeráticos em sua margem SW, como dos conglomerados cretácicos. A existência de diopsídio nos aluviões, mineral de reconhecida baixa resistência no meio fluvial, indica ainda o aporte de materiais das intrusões ultrabásicas em plena atividade e que, se algumas das intrusões fossem mineralizadas, também estariam fornecendo diamantes para os depósitos aluvionares recentes. 


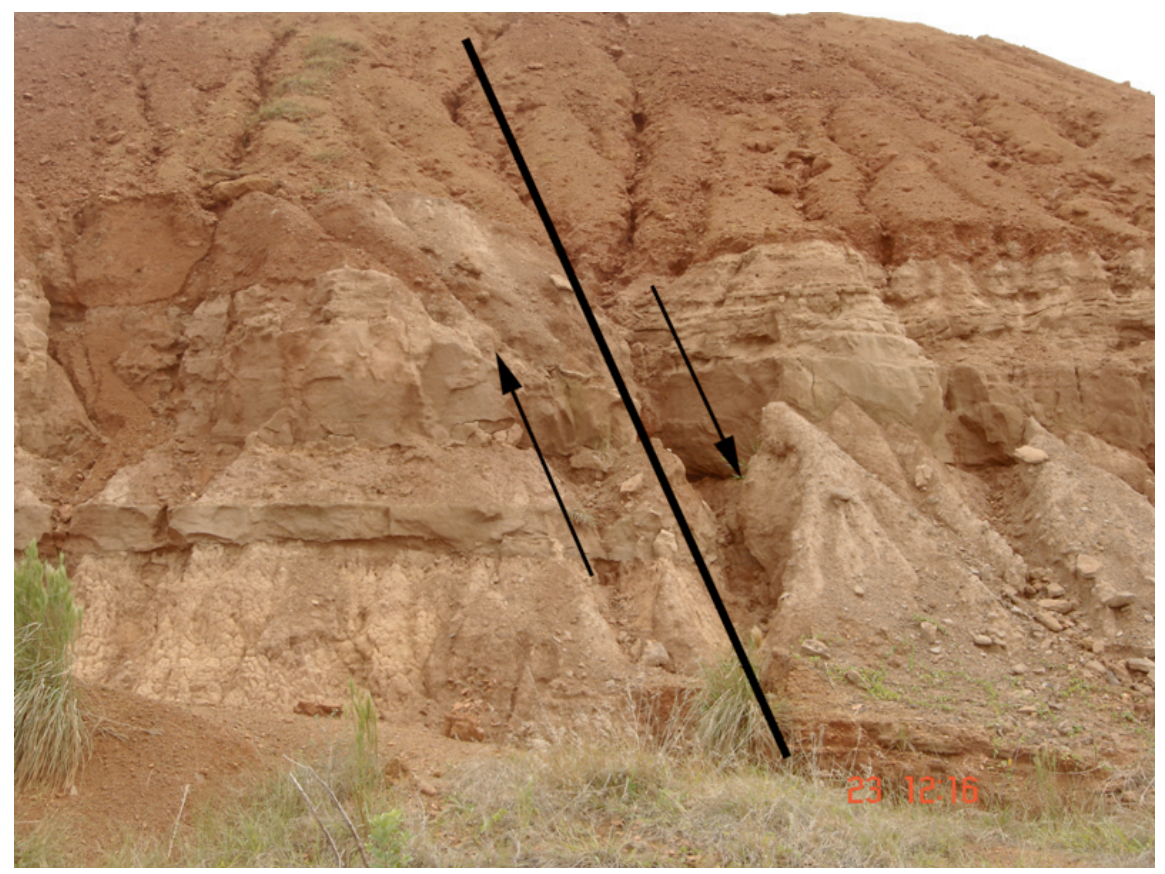

Foto 7: Deslocamento por falha normal das camadas da Formação Capacete (Cretáceo Superior), no Morro das Mesas, MG-188 a leste da área, evidenciando a existência de atividades pós-cretácicas (neotectônicas) na região em aprȩ̧o.

\section{CONCLUSÃO}

Deve-se ressaltar a reestruturação tectônica ocorrida no final do Mesozóico, promovida a partir de movimentos ascensionais epirogenéticos que modificaram o relevo e reativaram os processos deposicionais no âmbito da Bacia Sanfranciscana. Contribuições das unidades pré-cambrianas em associação aos materiais gerados por magmatismo intrusivo e extrusivo, determinaram a formação de espessos pacotes de sedimentos clásticos e piroclásticos, depositados em rios de alta energia e leques aluviais. Esses depósitos clásticos foram acompanhados por intenso aporte de produtos vulcânicos representados por tufos e sedimentos cineríticos, constituindo a Formação Capacete.

Após longo período de estabilidade tectônica, reativações locais durante o início do Cenozóico, estabelecidas sobre as mesmas estruturas regionais, determinaram novo ciclo de sedimentação, possivelmente condicionada por processos neotectônicos. Este ciclo propiciou o retrabalhamento dos sedimentos cretácicos através da formação de rios efêmeros e (novos) leques aluviais com sentidos direcionais S-N e SW-NE, originando os depósitos fanglomeráticos.

Tal evento também foi responsável pelo controle estrutural do curso do Rio Douradinho, seguindo antigas linhas de fraqueza reativadas, onde ocorreu expressiva sedimentação aluvionar recente com aporte de minerais de filiação kimberlítica, bem como diamantes. Assim, os economicamente significativos placers diamantíferos, em íntima associação aos depósitos fanglomeráticos, são fatores que permitem considerar a existência de fontes proximais para a mineralização. Essa fonte, por conseguinte, poderia estar relacionada a algumas das inúmeras intrusões kimberlíticas que ocorrem na região.

\section{REFERÊNCIAS BIBLIOGRÁFICAS}

ALMEIDA F.F.M. 1977. O Cráton do São Francisco. Revista Brasileira de Geociências, 7:349-364.

ANDRADE K.W. 2008. Geologia da Região Diamantífera do Rio Douradinho, ao Sul de Coromandel-MG. Belo Horizonte, Monografia de Graduação, IGC-UFMG, 101p.

BARBOSA O. 1991. Diamante no Brasil: Histórico, Ocorrência, Prospecção e Lavra. Brasília, Ed. CPRM, 136p.

BARBOSA O., Braun O.P.G., Dyer R.C., Cunha C.A.B.R. 1970. Geologia da região do Triângulo Mineiro. Rio de Janeiro, DNPM/DPFM, Boletim 136, 140p.

CAMPOS J.E.G. \& Dardenne M.A. 1997a. Estratigrafia e sedimentação da Bacia Sanfranciscana: uma revisão. Revista Brasileira de Geociências, 27:269-282.

CAMPOS J.E.G. \& Dardenne M.A. 1997b. Origem e evolução tectônica da Bacia Sanfranciscana. Revista Brasileira de Geociências, 27:283-294.

CAMPOS NETO M.C. 1984. Litoestratigrafia e evolução paleogeográfica dos grupos Canastra e Paranoá (região VazanteLagamar, MG). Revista Brasileira de Geociências, 14:81-91.

CHAVES M.L.S.C. 1991. Seqüências cretácicas e mineralizações diamantíferas no Brasil Central: considerações preliminares. Geociências, 10:231-245.

CHAVES M.L.S.C. \& Bottino E.C.C. 2000. Evolução geológica multifásica dos depósitos diamantíferos da região de Jequitaí, Minas Gerais. Geociências, 19:197-208.

CHAVES M.L.S.C., Karfunkel J., Svisero D.P. 1998. Sobre a polêmica de origem do diamante na Serra do Espinhaço (Minas Gerais): um enfoque mineralógico. Revista Brasileira de Geociências, 28:285-294.

CHAVES M.L.S.C., Benitez L, Veiga B.N., Moreira L.A. 2005. Microdiamantes da bacia do Rio Douradinho (Coromandel, MG): morfologia primária e aspectos de dissolução. In: Simpósio Brasileiro de Geologia do Diamante, 4, Anais do..., Diamantina, p.39-42.

CHAVES M.L.S.C., Benitez L., Chambel L. 2006. Análise 
comparativa dos aspectos superficiais de populações de diamantes nas províncias da Serra do Espinhaço e do Alto Paranaíba (MG). In: Congresso Brasileiro de Geologia, 43, Coletânea de Trabalhos Completos do..., Aracaju, p.807-811.

DAVIS G.L. 1977. The ages and uranium content of zircons from kimberlites and associated rocks. In: International Kimberlite Conference, 2, Extended Abstracts of.., Santa Fe (New MexicoUSA), p.78-80

ETCHEBEHERE M.L.C., Saad A.R., Fulfaro V.C. 2007. Análise da bacia aplicada à prospecção de água subterrânea no Planalto Ocidental Paulista, SP. Geociências, 26: 229-247.

FUCK R.A., Pimentel M.M., Del'Rey-Silva L.J.H. 1994 Compartimentação tectônica na porção oriental da Província Tocantins. In: Congresso Brasileiro de Geologia, 38, Anais do..., Balneário Camboriú, p.215-216.

HEILBRON M., Valeriano C., Zimbres E., Chrispin S.J., Simões L.S.A., Souza M.A.T. 1987. O contato basal do Grupo Canastra entre Itaú de Minas e Carmo do Rio Claro, MG. In: Simpósio de Geologia de Minas Gerais, 4, Anais do..., Belo Horizonte, p.179-198.

HEINECK C.A., Leite C.A.S., Silva M.A., Vieira V.S. 2003. Mapa geológico do Estado de Minas Gerais, Escala 1:1.000.000. Belo Horizonte: Convênio COMIG/CPRM, 2003, 1 folha.

LADEIRA E., Braun O.P.G., Cardoso R. N., Hasui Y. 1971. O Cretáceo em Minas Gerais. In: Congresso Brasileiro de Geologia, 25, Anais do..., São Paulo, p.15-31.

PENHA U.C., Karfunkel J., Angeli N. 2005. Diamondiferous deposits in the Jequitaí area (Minas Gerais, Brazil): a consequence of neotectonic processes. N. Jb. Geol. Paläont. Abh., 236:207224.

MAGALHÃES Jr. A.P. \& Trindade E.S. 2005. Morfodinâmica fluvial cenozóica em zonas de contato entre faixas móveis e cunhas tectônicas na região sul de Minas Gerais. Geonomos, 13:59-74

PEREIRA R.S. 2007. Craton do São Francisco, kimberlitos e diamantes. Brasília, Tese de Doutorado, IG-UnB, 200p.

PEREIRA R.S. \& Fuck R.A. 2005. Archean nucleii and the distribution of kimberlites and related rocks in the São Francisco Craton, Brazil. Revista Brasileira de Geociências, 35:93-104.

READ G., Grutter H., Winter S., Luckman N., Gaunt F., Thomsen F. 2004. Stratigraphic relations, kimberlite emplacement and lithospheric thermal evolution, Quiricó Basin, Minas Gerais State, Brazil. Lithos, 77:803-818.

SAADI A. 1993. Neotectônica da Plataforma Brasileira: esboço e interpretações preliminares. Geonomos, 1:1-15.

SEER H.J. 1999. Evolução Tectônica dos Grupos Araxá, Ibiá e Canastra na sinforma de Araxá, Minas Gerais. Brasília, Tese de Doutorado, IG-UnB, 267p.

SEER H.J. \& Dardenne M.A. 2000. Tectonoestratigraphic terrane analysis on Neoproterozoic times: the case study of the Araxá Synform, Minas Gerais, Brazil - implications to the final collage of the Gondwanaland. Revista Brasileira de Geociências, 30:78-81.

SEER H.J., Brod J.A., Fuck R.A., Pimentel M.M., Boaventura G., Dardenne M.A. 2001. O Grupo Araxá em sua área-tipo: um fragmento de crosta oceânica Neoproterozóica na Faixa de Dobramentos Brasília. Revista Brasileira de Geociências, 31:385-396.

SGARBI G.N.C. 1989. Geologia da Formação Areado, Cretáceo Médio a Inferior da Bacia do São Francisco, oeste de Minas Gerais. Rio de Janeiro, Dissertação de Mestrado, IG-UFRJ, 342p.

SGARBI G.N.C., Sgarbi P.B.A, Campos J.E.G, Dardenne M.A, Penha U.C. 2001. Bacia Sanfranciscana: registro fanerozóico da Bacia do São Francisco. In: Pinto C.P. \& Martins-Neto M.A. Bacia do São Francisco; Geologia e Recursos Naturais. Belo Horizonte, Ed. SBG-MG, p.93-138.

SGARBI P.B.A., Gaspar J.C., Valença J.G. 2000. Brazilian kamafugites. Revista Brasileira de Geociências, 30:413-416.

SIMÕES L.S.A. \& Valeriano C. 1990. Porção meridional da Faixa Brasília: estágio atual do conhecimento e problemas de correlação tectono-estratigráfica. In: Congresso Brasileiro de Geologia, 36, Anais do..., Natal, p.2564 -2575.

SUGUIO K., Svisero D.P., Felitti Filho W. 1979. Conglomerados polimíticos diamantíferos de idade cretácica de Romaria (MG): um exemplo de sedimentação de leques aluviais. In: Simpósio Regional de Geologia, 2, Resumos do..., Rio Claro, p.217-229.

VALERIANO C.M. \& Simões L.S.A. 1997. Geochemistry of proterozoic mafic rocks from the Passos nappe (Minas Gerais, Brazil): tectonic implications to the evolution of the southern Brasília Belt. Revista Brasileira de Geociências, 27:99-110. 